\title{
Gill disease of crucian carp Carassius carassius associated with an unidentified protozoan
}

\author{
S. J. Ball ${ }^{1}$, D. A. Zacharek ${ }^{1}$, A. F. Dearsley ${ }^{2, *}$, Janet F. Moore ${ }^{2}$ \\ ' Department of Biosciences, Polytechnic of East London, Romford Road, Stratiord, London E15 4LZ, United Kingdom \\ ${ }^{2}$ National Rivers Authority, Thames Region, Aspen House, Crossbrook Street, Waltham Cross, Hertfordshire, United Kingdom
}

\begin{abstract}
A light and scanning electron-microscopic study of the gills of diseased pure crucian carp Carassius carassius L. from the Thames Water Authority area, UK, revealed the existence of a protozoan parasite within the cells of the gill lamellae.
\end{abstract}

Over the past 12 yr a disease causing fatalities in pure crucian carp Carassius carassius stocks in the Thames Water Authority area has been detected in 14 different batches of fish. The disease was first observed in June 1978 in fish from the Fairland's Valley Lakes, Stevenage (British National Grid reference, TL 255240). Other recorded areas are as follows: $\mathrm{TQ}$ 544937, 11.9. 1987; TL $517194,29.10 .1979 ;$ TL 555307.27 .6 .1981 ; TL 422998, 10.8. 1981; TQ 247975, 29. 11. 1984; TQ 055717, 1.7. 1985; TQ 193494, 17.7. 1985; TL 421127, 27. 3. 1985; TQ 565962, 15. 8. 1985; TQ 273677, 12.9. 1985; TQ 483808, 15.5. 1986; 2 batches of fish from commercial fish suppliers, Billericay, 9. 12. 1982 and Bletchingley, 24. 6. 1985; the exact source of these fish is unknown.

The causative organism has not yet been identified, but in all diseased fish an enigmatic protozoan was detected within globoid-like structures on the gill lamellae. This organism is considerd to be the aetiological agent.

Gills from moribund crucian carp, killed by placing them in water containing $300 \mathrm{ppm}$ of benzocaine (Laird \& Oswald 1975), were fixed in alcoholic or aqueous Bouin or $10 \%$ formalin for light microscopy. Sections were stained with Heidenhain's iron haematoxylin or Ehrlich's haematoxylin and eosin. For scanning elec-

\footnotetext{
- Present address: Thames Water, Quality Assurance Section, Reading Bridge House, Vastern Road, Reading, Berkshire, UK
}

tron microscopy gills were fixed in $2.5 \%(\mathrm{v} / \mathrm{v})$ glutaraldehye in cacodylate buffer at $\mathrm{pH} 7.2$, postfixed in $1 \%(\mathrm{w} / \mathrm{v})$ osmium tetroxide in the same buffer, dehydrated through an acetone gradient and critical point dried.

Infected and uninfected gill lamellae are shown in Fig. 1. The smooth surface of the leaf-like uninfected lamellae (Fig. 1a, b) is altered by the enlargement of infected epithelial cells (Fig. 1c to f). No bias distribution of the globoid structures was noted as the lesions appeared randomly distributed. Cellular hyperplasia of the lamellae was often present, especially at the junction with the gill filament, indicated in Fig. 1f, and this occasionally resulted in fused lamellae.

Fresh scrapings from infected gills revealed up to 4 organisms per globoid structure. The organism was amoeboid in appearance, ca $17 \mu \mathrm{m}$ long and 5 to $7 \mu \mathrm{m}$ wide, contained refractile granules and was highly contractile moving in a rhythmic shuttle flow amoeboid manner. This movement is depicted in Fig. 2.

The signs of the disease include emaciation, sunken eyes, lack of mucus and erosion of fin membranes. Infected fish usually die. Most deaths occur in the summer months and the greatest frequency of mortality is at temperatures over $20^{\circ} \mathrm{C}$.

On 4 separate occasions uninfected crucian carp were placed with infected stock and the time taken for them to become moribund ranged from 38 to $124 \mathrm{wk}$. Parasites were observed in all moribund fish. The shortest time under these conditions for uninfected carp to become infected, as detected by microscopic examination of gill tissue, was $78 \mathrm{~d}$ (at 15 to $20^{\circ} \mathrm{C}$ ), and the shortest period from introduction to death was $29 \mathrm{wk}$.

The parasite could be specific to pure crucian carp because a $15 \mathrm{~cm}$ rudd maintained with infected stock 

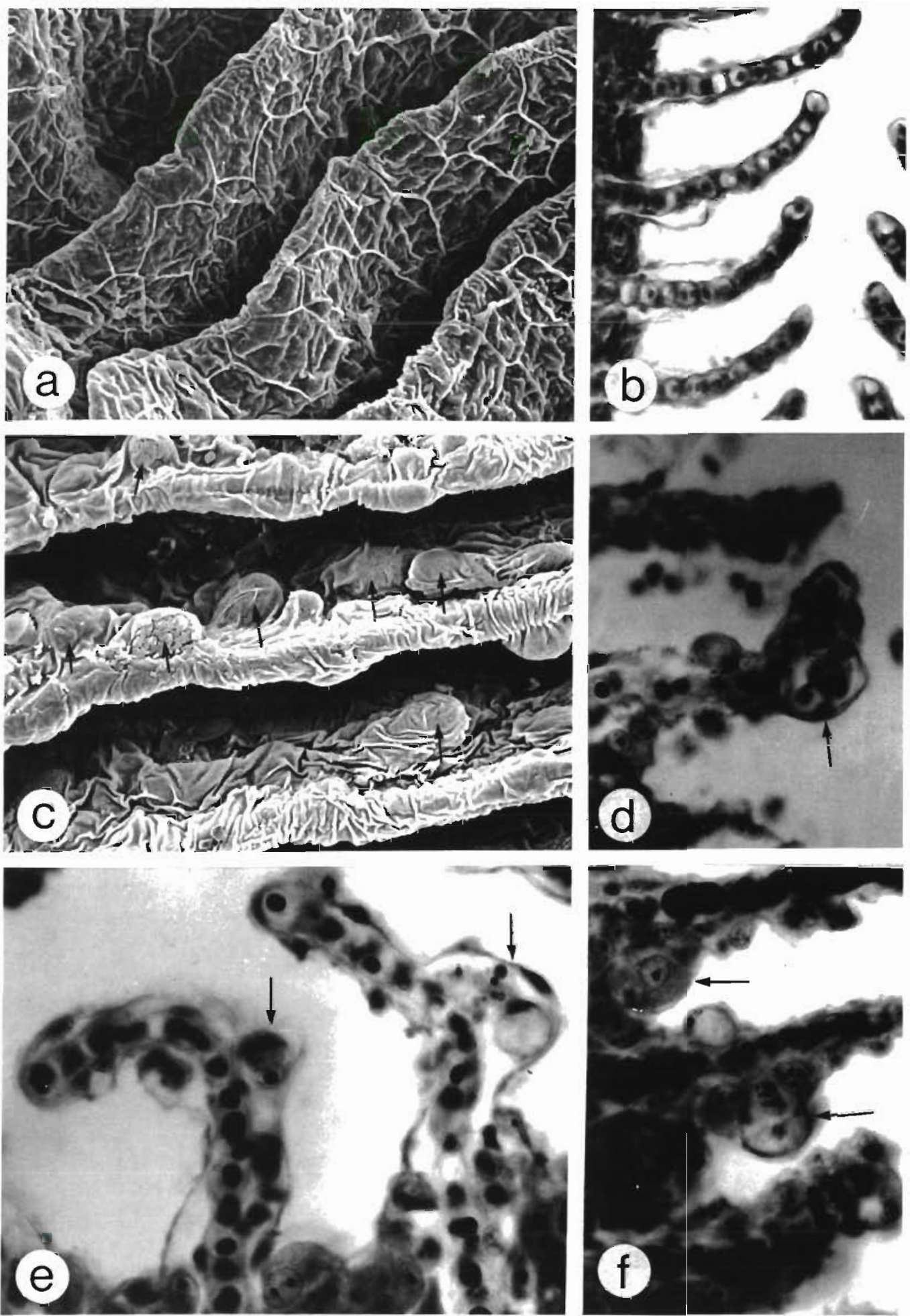

Fig. 1. Carassius carassius. Surface views and sections of crucian carp gill lamellae. $(a, c)$ Scanning electron micrographs (show signs of preparation-induced shrinkage); $(b, d, e, f)$ photomicrographs of $5 \mu \mathrm{m}$ sections stained $H \&$ E. $(a, b)$ uninfected specimens; $(c, d, e, f)$ infected lamellae with globoid structures arrowed. Magnifications are: (a) $\times 660$, (b) $\times 200$, (c) $\times 660$. (d) $\times 200$, (e) $\times 400$, (f) $\times 220$ 


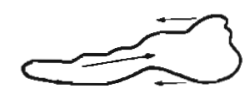

a
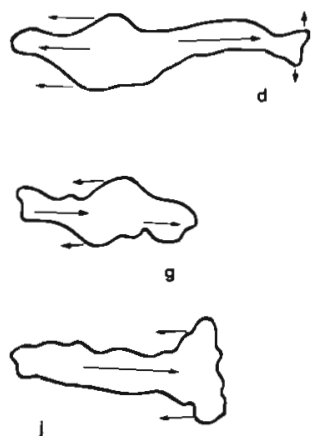

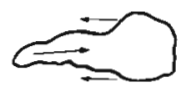

$b$
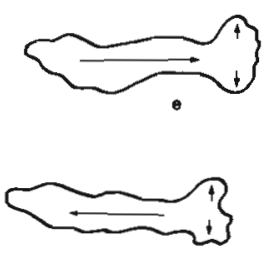

h
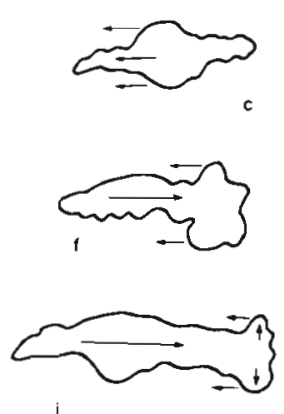

Fig. 2. Movement sequence drawn from video recording of organism from lamellae scrape. Arrows indicate direction of cytoplasm movement

for $22 \mathrm{mo}, 2$ tench maintained for $7 \mathrm{mo}$, and a $19 \mathrm{~cm}$ crucian/common carp hybrid maintained with infected stock for 20 mo all remained uninfected.

Responsible Subject Editor: Professor W. Körting, Hannover, F. R. Germany

\section{LITERATURE CITED}

Laird, L. M., Oswald R. L. (1975). A note on the use of Benzocaine (ethyl p-aminobenzoate). J. Inst. Fish. Mgmt 6: 92-94

Manuscript first received: June 3,1989

Revised version accepted: February 28, 1990 